\title{
Authoring Game-Based Adaptive Units of Learning with IMS Learning Design and <e-Adventure>
}

Citation for published version (APA):

Burgos, D., Moreno-Ger, P., Sierra, J. L., Fernández Manjón, B., \& Koper, R. (2007). Authoring Game-Based Adaptive Units of Learning with IMS Learning Design and <e-Adventure> International Journal of Learning Technology, 3(3), 252-268. https://doi.org/10.1504/lJLT.2007.015444

\section{DOI:}

10.1504/IJLT.2007.015444

Document status and date:

Published: 17/10/2007

Document Version:

Peer reviewed version

\section{Document license:}

CC BY-NC-ND

Please check the document version of this publication:

- A submitted manuscript is the version of the article upon submission and before peer-review. There can be important differences between the submitted version and the official published version of record. People interested in the research are advised to contact the author for the final version of the publication, or visit the DOI to the publisher's website.

- The final author version and the galley proof are versions of the publication after peer review.

- The final published version features the final layout of the paper including the volume, issue and page numbers.

Link to publication

\section{General rights}

Copyright and moral rights for the publications made accessible in the public portal are retained by the authors and/or other copyright owners and it is a condition of accessing publications that users recognise and abide by the legal requirements associated with these rights.

- Users may download and print one copy of any publication from the public portal for the purpose of private study or research.

- You may not further distribute the material or use it for any profit-making activity or commercial gain

- You may freely distribute the URL identifying the publication in the public portal.

If the publication is distributed under the terms of Article $25 f a$ of the Dutch Copyright Act, indicated by the "Taverne" license above, please follow below link for the End User Agreement:

https://www.ou.nl/taverne-agreement

Take down policy

If you believe that this document breaches copyright please contact us at:

pure-support@ou.nl

providing details and we will investigate your claim.

Downloaded from https://research.ou.nl/ on date: 26 Apr. 2023 


\title{
Authoring game-based adaptive units of learning with IMS Learning Design and <e-Adventure>
}

\section{Daniel Burgos*}

Educational Technology Expertise Centre (OTEC)

Open University of the Netherlands

Valkenburgerweg, 177

6419AT Heerlen, the Netherlands

E-mail: daniel.burgos@ou.nl

*Corresponding author

\section{Pablo Moreno-Ger, José Luis Sierra and Baltasar Fernández-Manjón}

Department of Software Engineering and Artificial Intelligence

Complutense University of Madrid

Profesor José Garcia Santesmases s/n

28040 Madrid, Spain

E-mail: pablom@fdi.ucm.es

E-mail: jlsierra@fdi.ucm.es

E-mail: balta@fdi.ucm.es

\section{Rob Koper}

Educational Technology Expertise Centre (OTEC)

Open University of the Netherlands

Valkenburgerweg, 177

6419AT Heerlen, the Netherlands

E-mail: rob.koper@ou.nl

\begin{abstract}
Electronic games and simulations (eGames) are a valuable support for adaptive learning. This adaptation can be based on different inputs, such as the user's performance, behaviour or cognitive load. Both adaptation and eGames can be modelled with IMS Learning Design (IMS LD) or integrated from an external resource. In this article we show the relation between IMS $\mathrm{LD}$ and the <e-Adventure > Project when it comes to authoring adaptive Units of Learning (UoLs) integrated with eGames. We first describe the challenges of this objective and the several different solutions on authoring and integration. We also describe the content-centred authoring approach in <e-Adventure>, and the need for a communication service with IMS LD that makes a bidirectional influence on the user's adaptive learning experience. At the end, we describe a practical example that illustrates how an adaptive IMS LD UoL with an integrated <e-Adventure $>$ eGame is developed.
\end{abstract}

Keywords: authoring; adaptive learning; IMS Learning Design; IMS LD; $<$-Adventure>; game-based learning; learning technology. 
Reference to this paper should be made as follows: Burgos, D., Moreno-Ger, P., Sierra, J.L., Fernández-Manjón, B. and Koper, R. (2007) 'Authoring game-based adaptive units of learning with IMS Learning Design and <e-Adventure>', Int. J. Learning Technology, Vol. 3, No. 3, pp.252-268.

Biographical notes: Dr. Daniel Burgos works as an Assistant Professor at the Open University of the Netherlands, after having worked 14 years as a Teacher, Multimedia and Game Developer, and Academic Manager in Europe and South America, as well as with his own company. He is mainly focused on adaptive e-learning, IMS Learning Design, eGames and learning networks, and he is involved in the research projects ProLearn and TenCompetence. More information at www.danielburgos.eu.

Pablo Moreno-Ger, MSc, is a member of $\langle\mathrm{e}-\mathrm{UCM}\rangle$, the e-learning research group at the Complutense University of Madrid (UCM). His research interests include e-learning technologies and the integration of video games and simulations in learning environments. He is currently working on his $\mathrm{PhD}$ thesis in the Department of Software Engineering and Artificial Intelligence and leading the development of the <e-Adventure> educational game engine. More information at www.e-ucm.es/people/pablo.

Dr. José Luis Sierra is an Assistant Professor in the Department of Software Engineering and Artificial Intelligence (DISIA) at the Complutense University of Madrid (UCM), Spain. He is a member of $\langle$ e-UCM $>$, the e-learning research group at the UCM. His research interests include e-learning technologies, domain-specific languages and mark-up languages. He received his $\mathrm{PhD}$ in Computer Science from the UCM. More information at www.e-ucm.es/ people/jlsierra.

Dr. Baltasar Fernández-Manjón is an Associate Professor in the DISIA at the UCM, where he co-leads the $<\mathrm{e}-\mathrm{UCM}>$ group. He is also the Vice Dean of Research and Foreign Relations at the Computer Science School of this university. His main research interests are e-learning technologies, educational uses of mark-up technologies, application of educational standards and user modelling. He received his PhD in Physics from the UCM. More information at www.e-ucm.es/people/balta.

Professor Dr. Rob Koper is a Full Professor of Educational Technology and the Head of the Development Programme at OTEC, Open University of the Netherlands. His research is focused on personalised instructional, web-based learning environments and self-organised distributed learning networks for lifelong learning, including the use of interoperability specifications and standards. More information at www.learningnetworks.org.

\section{Introduction}

IMS Learning Design (IMS LD) is focused on providing a flexible specification to model several pedagogies. Two of the main objectives of this specification are to model adaptive learning and to provide interoperability. IMS LD allows the modelling of highly adaptive Units of Learning (UoLs) in order to provide personalised learning experiences, but UoL authoring is a complex task, mainly due to the lack of high-level IMS LD 
authoring tools. This problem becomes more complex when we try to integrate a UoL with external resources developed with different technologies and to establish a communication flow between both parts.

On the other hand, electronic games and simulations (eGames) are a useful resource when dealing with adaptation and e-learning. In addition to the motivational enhancements to the learning process, eGames can provide adaptive content and fully personalised itineraries. With this potential in mind, and with the objective of simplifying the authoring process for educational games, the <e-Adventure> Project provides a rich notation and an educational game engine targeted at a very specific game genre: Point-and-Click graphical adventure games.

Drawing on these ideas, in this article we propose an authoring approach for adaptive IMS LD UoLs with embedded eGames. Indeed, the main obstacle to the integration of external software applications and modules developed outside IMS LD is the increase in the complexity of the authoring process. We first describe IMS LD and the challenges it presents from an authoring perspective. Then we introduce <e-Adventure $>$ and its authoring approach, which results from the marriage between descriptive mark-up languages and domain-specific languages. Next we adopt a similar authoring approach for the integration of <e-Adventure> eGames and IMS LD. All these aspects are illustrated with an example regarding an adaptive IMS LD UoL with an eGame embedded. Finally we provide some conclusions and outline some lines of future work.

\section{An adaptive learning environment with IMS Learning Design and eGames}

\subsection{Adaptive learning and the IMS Learning Design specification}

IMS LD (2003) is a specification to represent and encode learning structures and methods for learners and teachers. Furthermore, IMS LD is focused on the design of pedagogical methods able to manage learning activities linked to learning objects within a learning flow (Koper and Tattersall, 2005). This learning flow consists of plays, acts, activities, activity structures and environments and it is flexible enough to provide several personalised itineraries depending on the role assigned or on a set of rules.

The usual life cycle starts with a lesson plan modelled according to the IMS LD specification, defining roles, learning activities, services and several other elements, inside an XML document (W3C, 2003) called Manifest (Tattersall et al., 2003). An information package written in IMS Content Packaging (IMSCP, 2001) is used as a container for the resources and links them with the IMS LD structure. Later, the Manifest is packaged with the nested resources in a compressed ZIP file, meaning a UoL. Several examples are available in OUNL (2002) and LN4LD (2005).

Therefore, the UoL is distributed as a compressed file with (a) an XML Manifest, describing methods, plays, acts, roles, activities, environments, properties, conditions and/or notifications of the LD specification and also pointing to the related resources; and (b) a set of files or resources mentioned in the XML Manifest. Once the UoL is validated, published and run in a player, the player will coordinate the teachers, the students and the activities during the learning process (Koper and Tattersall, 2005). 
IMS LD consists of three levels (Figure 1): Level A is the main part of the specification as it provides the base line for building any UoL with the elements Method, Plays, Acts, Roles, Role-Plays, Learning activities, Support activities and Environments; Level B adds some features to create more complex lesson plans using Properties, Conditions, Calculations, Monitoring services and Global elements; and Level C adds Notifications. Each layer is built upon the previous one (Koper and Burgos, 2005).

Figure 1 IMS Learning Design and the three levels

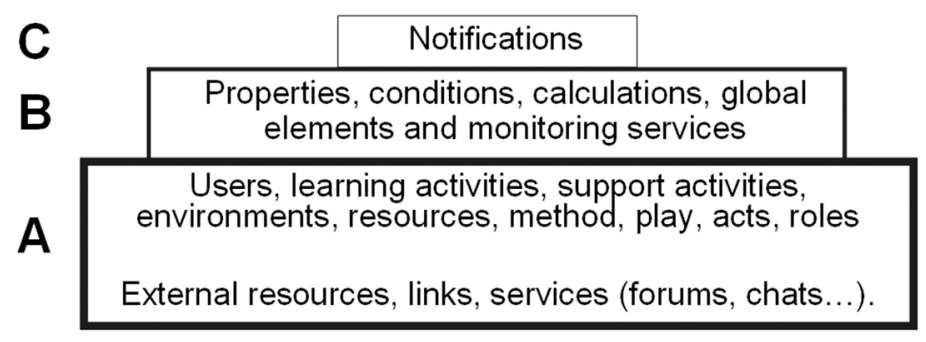

In addition to the basic structure of Level A, the elements in Level B are actually the key for more expressive UoLs (for instance, based on adaptation or collaboration), as they combine several features that encourage and make the content and the learning flow more flexible (Koper and Burgos, 2005; Specht and Burgos, 2006). Furthermore, the combination of these elements allows for the modelling of several classical adaptive methods (e.g., reuse of pedagogical patterns, adaptability, navigational guidance, collaborative learning, contextualised and mobile distributed learning, adaptation to stereotypes), making use of different structural elements of IMS LD, like Environment, Content, User groups and Learning flow.

Every single step between the creation and the use of a UoL needs an IMS LD-compliant tool. The UoLs can be created with general-purpose editors, such as XML Spy (Altova, 2006), or with specific IMS LD editors, such as CopperAuthor (Van der Vegt, 2005), Cosmos (Miao, 2005) or Reload LD Editor (Bolton, 2004); and they can be run with several tools and engines, such as CopperCore (Vogten and Martens, 2005) or SLeD (OUUK, 2005). However, current tools do not allow for easy editing and a significant effort is still needed to create adaptive IMS LD UoLs comprising level B and C constructs (Burgos et al., 2006a). They make the creation of adaptive UoLs technically possible, but too difficult for a nontechnical user. A higher-level layer with a more visual metaphor is still missing, although some initiatives are being taken. For instance, the TENCompetence Project (TENCompetence, 2005) and the Complutense University (UCM, 2006) are developing a visual LD Editor each. The conception of these tools will ultimately rely on the domain concepts behind the specification, which are incarnated in the domain-specific XML binding.

\subsection{Integration of eGames with IMS LD}

Electronic games and simulations (eGames) engage people (Prensky, 2001; Garris et al., 2002; Squire, 2002). EGames improve motivation and involvement, which results in a deeper learning experience (Malone and Lepper, 1987; Cordova and Lepper, 1996). They 
provide the player with a long list of benefits: fun, interactivity, problem solving, user involvement, motivation and creativity, to mention a few (Prensky, 2001). They also awaken personal feelings and emotions in the players, such as wonder, power or aggression, and provide support for the development of personal competences like focused goals, rules, tasks, affiliation, choice, or the absence of adverse consequences in the case of a wrong choice (Squire, 2002).

EGames also provide input, output and feedback in real time (Rieber, 1996; Laurillard, 1998), which are used in adaptive learning, e.g., choosing the next action to take or the contextualised help provided. In order to achieve the educational objectives, we can use various interactive learning techniques - i.e., learning from mistakes, goal-oriented learning, role playing and constructivist learning (Prensky, 2001; Gee, 2003) - within and/or around the game itself. The main goal is to make the game a fully integrated activity within the whole learning process, instead of remaining an isolated stand-alone resource (Provenzo, 1991; Gee, 2005). In doing so, generic games, as well as specific educational games, can be used as an interlaced element throughout the learning experience, thus increasing the educational threshold (Burgos et al., 2006c).

However, when eGames (or other external systems) are introduced in an e-learning environment, their use is often isolated from e-learning systems and other information packages (e.g., IMS LD, IMS CP, SCORM) (Eskelinen, 2001; Squire, 2002; Jenkins and Squire, 2003). If we model a UoL containing several activities and one of them (for instance, Activity-Game) is a game, the game will be executed separately from the main flow. The students will play the game, but no connection is established with the previous activity or the following. Therefore, the game is incorporated to a learning flow but no further communication is established with it. In this sense, the eGame is another learning object but with a lack of interaction with the rest of the setting, and is unable to influence the learning flow. In terms of communication, there is no difference between this game and other more static resources, such as a document, a video or a link to a web page.

On the other hand, closer integration allows for pedagogical improvements as well as a better contextualised learning path (Richards, 2005; Burgos et al., 2006c). In this approach, the activity previous to the Activity-Game can provide some input to the game. For instance, the learner answers a quiz and the final score is sent directly to the game. Then, the game could start with an adaptive setting based on this input. Thus, if the score is less than a specific threshold, the starting level is for beginners; if the score is higher, the starting level is for advanced players. During the game, a list of values of properties is sent to the learning flow to provide a detailed report after the game and/or to influence the next action to take (for instance, choosing one learning path out of several possibilities).

Therefore, the game is a fully operational part of the learning flow, able to send and receive information to and from the UoL, via a communication dispatcher, and each layer can interact with the other, hence personalising the learning experience, influencing the run-time and modifying features in both parts during the execution of the run (Figure 2).

However, this task is not necessarily easy or cost-effective. If an author wishes to include an eGame in a UoL, enabling such a communication is a major issue, as it would require modifying the source code of the executable games to support this communication. Additionally, even if the game is capable of establishing such a communication, eGames and the UoL may be developed independently, which means there has to be a connection between the variables being accounted for in the UoL and in the eGame. Thus, the rest of this work deals with how the development process for 
eGames can be facilitated for content authors and how it is possible to configure (without programming knowledge) a generic communication dispatcher that translates values so that the eGame and the UoL can understand each other.

Figure 2 General architecture of communication between the learning flow and the game compared to static content. The communication dispatcher is responsible for handling the communication between the game and the learning flow

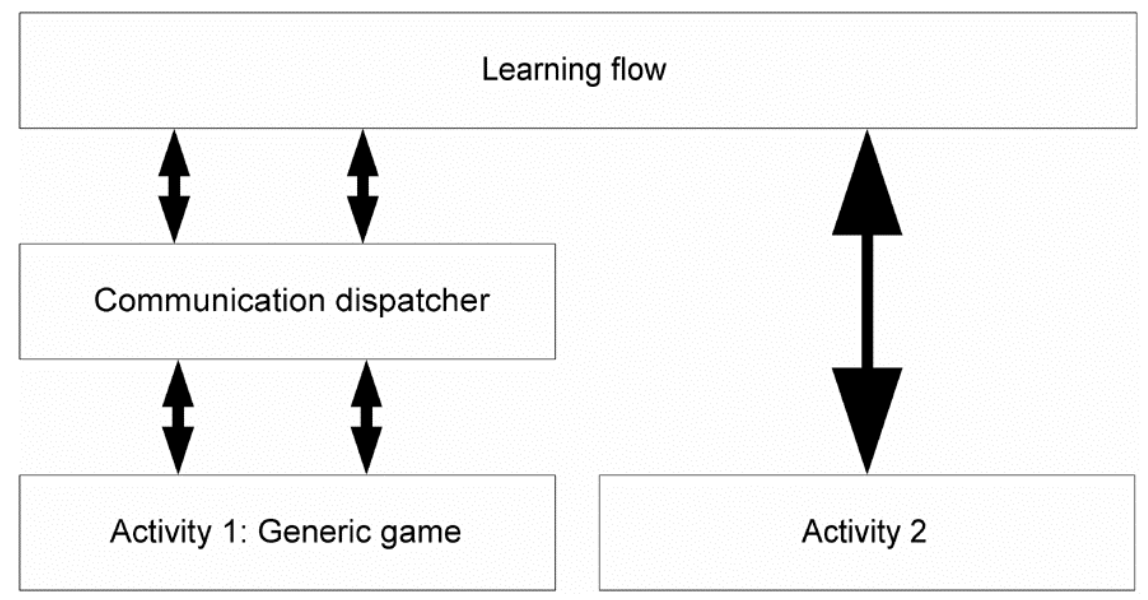

\section{The $<$ e-Adventure $>$ Project}

The main goal of the <e-Adventure > Project is to apply a documental approach (Sierra et al., 2004; 2005a-b) to the authoring of educational graphical adventure video games (often also referred to as point-and-click adventure games). This documental approach promotes an authoring strategy that results in the marriage between descriptive mark-up languages (Coombs et al., 1987), such as are used in the publishing domain, and domain-specific languages, as proposed by the software engineering community (Mernik et al., 2005). Indeed, applications are described using documents. These documents are marked up with suitable domain-specific mark-up languages, and final applications are produced using suitable application generators. This approach has proven very useful in enabling the authoring by domain-experts of many different content-intensive applications in many different domains.

Having identified the high development cost and the requirement of programming skills as two of the main shortcomings in authoring educational games, the key objective of <e-Adventure $>$ is to allow an author without a strong technical background to produce and maintain an entire game as a document using an easy-to-understand language, which is then fed to an interpreter (the <e-Adventure > engine) that produces a fully functional game.

The language is an XML application - i.e., an XML-based mark-up language defined with an XML document grammar: a DTD or a Schema. The author uses this language to describe the environment, characters, objects and situations that form the game, just as another author could use a more conventional mark-up language (e.g., LaTex or Docbook) in preparing a manuscript. The objective is to allow an author 
to build an executable game without needing previous background in programming. All he/she would need is basic knowledge on how to use a computer, a text editor, a few notions of XML and familiarity with <e-Adventure> syntax. In this section we will give a high-level description of the philosophy behind the project. Further details on $<\mathrm{e}$-Adventure> (formerly known as <eGame>) are described in Martinez-Ortiz et al. (2006) and Moreno-Ger et al. (2006; 2007).

\subsection{The authoring process in $<e$-Adventure $>$}

Writing a document in the <e-Adventure> language should not feel like programming, but more like writing a story. This means that the author does not specify how the characters move or how the lighting works, but what the actual content of the game is (scenarios, items, conversations, etc.). Regardless of whether one uses a plain text editor or a more user-friendly editor with a lot of eye-candy, in our opinion this is the true advantage of <e-Adventure> for authoring: developing an eGame is equivalent to writing a document.

As depicted in Figure 3, the authoring process in the context of $<\mathrm{e}$-Adventure $>$ begins with the creation by the Instructors of a storyboard in natural language. There are a number of guidelines for the creation of the storyboard that facilitate the rest of the process as described in Moreno-Ger et al. (2007). Next, the Instructors, following the <eAdventure $>$ document grammar provided by the Developers (experts in computer science), add the mark-up directly onto the original storyboard. The result is an XML document, called the <e-Adventure > document, which makes the structure of the original storyboard explicit. This document will also include references to several art assets (such as graphics, animations or music) provided by a third kind of experts (the Artists), and which will be used in the production of the final video game. The <e-Adventure> document, together with the required art assets, is directly fed to the <e-Adventure $>$ engine (provided and maintained by the Developers) for their execution. Notice that the support of Artists and Developers brings to the approach the flexibility of a full-featured custom solution to the production of video games (indeed, the authoring environment can be specialised for each production scenario) while also preserving the authoring advantages of a domain-specific solution.

Figure 3 Authoring in <e-Adventure $>$

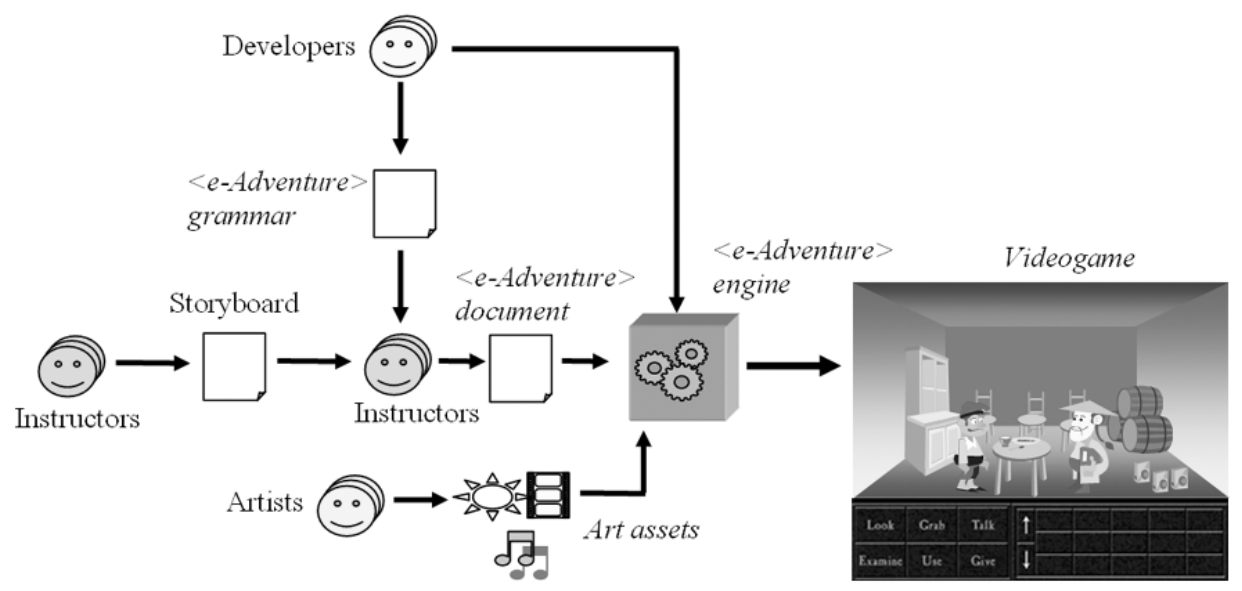




\subsection{The $<e$-Adventure $>$ language}

The <e-Adventure> language closely mirrors the typical structure that occurs in a storyboard for a point-and-click adventure game (see Figure 6 in Section 5.2 for an example of an <e-Adventure > document fragment). Following the traits of the genre, the basic unit of construction is the 'scene'. An <e-Adventure > storyboard (and thus the marked document) starts by describing all the scenes that make up the game, including the associated resources, their connections to other scenes and the description of the characters and objects that populate the scene.

The definition of items and characters is also very straightforward, focusing on their descriptions and the possible interactions that can be performed on them. An item can be roughly examined (a brief description), examined in detail (a more detailed description), combined with another object or given to another character. For further details about the $<$ e-Adventure> language, refer to Moreno-Ger et al. (2007).

\subsection{Game state}

Just describing the elements that form the game yields a plain game where every door is always open, every character always says the same things and every exit leads to the same place. For the game to be interesting, it is necessary to support the means to provide a sense of narration. We can achieve this by introducing a notion of 'state'. All the actions that we perform in the game should be able to affect future actions. Some objects may be hidden until something happens (e.g., the object appears only if the player has performed action $\mathrm{X}$ ); some exits may be locked (e.g., you cannot enter the library until you are admitted to the course or until you talk the secretary into letting you in); and a character may offer a different conversation (e.g., the secretary is more friendly after the player gives her a small gift).

From the perspective of the author, these interactions are conceptually modelled by allowing each interaction (with an object or character) to activate conditions or, in $<$-Adventure $>$ terminology, flags. Then, the author can add preconditions to any element of the game. Intuitively, the state at any given point of the game is the set of active flags, which are an indication of which relevant actions have already been performed. See Figure 6 in Section 5.2 for an example of using flags in an <e-Adventure> document.

\section{The communication between <e-Adventure > and IMS LD}

The use of <e-Adventure $>$ as an authoring environment for eGames addresses the issues related to the authoring of the games, but does not solve the authoring concerns regarding the integration of the games in the learning flow. As described in Section 2, the integration of eGames (implemented with <e-Adventure> or any other authoring methodology) is a complex task and raises a number of authoring issues. The basic problem is that when a learner is interacting with a specific UoL, the specification demands that the environment keep a record of the state of a number of variables, called properties, that can be used to alter the path of the learning flow. Likewise, eGames are often analysed in terms of game states which may or may not be directly expressible in terms of IMS LD properties. 
It is necessary to provide the means to communicate and to translate the information used within the UoL and the information used within the eGames, a task that in general terms would require a strong programming background.

However, <e-Adventure> supports a clear and narrow eGame model, in which information is stored and interpreted in a declarative fashion. The task of authoring the game is facilitated by the use of a domain-specific descriptive mark-up language that can be understood and applied without a programming background. The same ideas can be applied to the authoring of the information flow, thus allowing the nontechnical author to specify the communications that should take place between the eGame and the UoL in a declarative fashion. These specifications written by the author are interpreted by the communication dispatcher shown in Figure 2.

The rest of this section describes the documents that should be created by the author to specify the translations between properties in the UoL and game states.

\subsection{Mapping UoL properties to $<e$-Adventure> game states}

While authoring an adaptive eGame using <e-Adventure>, the game designer is required to implement that adaptation in terms of conditions over the state of the flags, since that is the mechanism used within <e-Adventure > to make conditional decisions at any point. Indeed, if the state of a number of flags is modified as indicated in Section 3.3, the game can exhibit a completely different behaviour. If defined carefully, these different behaviours can correspond to different adapted versions of the same game.

Likewise, the state of the learning process at the moment of launching the game relies on a number of properties defined in the UoL. Following this declarative authoring approach, the author can identify the relations between sets of properties and states in an XML file (see Figure 7 in Section 5.2 for an example). When the game is launched, the communication dispatcher depicted in Figure 2 uses this configuration file to translate the state of the properties within the UoL into an initial game state.

\subsection{Mapping <e-Adventure> game states to UoL properties}

Once the eGame has been designed and written using <e-Adventure>, instructors or learning designers can also prepare separate documents identifying those game states that are relevant from a pedagogical perspective and that should affect the state of the current UoL. Again, the problem lies in translating <e-Adventure> game states into states of the UoL. As in the previous subsection, we use a declarative approach to allow the instructor to identify the relations between states and sets of properties in another XML file, with a mark-up syntax which is an extension of that used in the internal assessment engine implemented by <e-Adventure> and described in Martinez-Ortiz et al. (2006). In Figure 8 of Section 5.2 we include an example.

Each entry in this file is a mapping between a game state and a set of values for some of the properties present in the UoL. The game state is represented as a Boolean expression on the flags as used in the <e-Adventure> language itself (see Section 3.3). Meanwhile, the properties in the UoL that need to be modified are expressed with a list of set-property elements identifying the property to be set and its new value.

Given the nature of this process, it is important to note that the separation between this mechanism and the definition of the game in terms of states conditioned by flags is wide enough to take an authoring approach in which the writer of the game and the 
instructor identifying the pedagogically relevant states need not be the same person. This mechanism can thus cater either to a scenario in which the instructor is creating a game on his or her own or to a scenario in which the instructor is part of a team that includes professional writers designing the game.

\section{A practical example of authoring and integration: The Art and Craft of Chocolate}

In order to demonstrate the aforementioned approach, we have developed an adaptive IMS LD UoL with an integrated eGame externally modelled with <e-Adventure > and a bidirectional communication flow resulting in a personalised learning path based on two inputs: the previous knowledge and the performance of the learner (Burgos et al., 2006b).

\subsection{Basics and layout}

In this UoL, called The Art and Craft of Chocolate - available at OUNL (2002) - the final goal is to learn some things about the world of chocolate from a practical point of view. The high-level structure of the UoL is sketched in Figure 4. The student must know the properties of the ingredients and the history of this product to make tasty sauces that can match the appropriate selection of meals and the expectations of the customers. The UoL includes an assessment quiz, an eGame as its main core, and a post-adaptive learning path.

Figure 4 Structure and dependencies of the UoL The Art and Craft of Chocolate, including the three stages of the embedded eGame

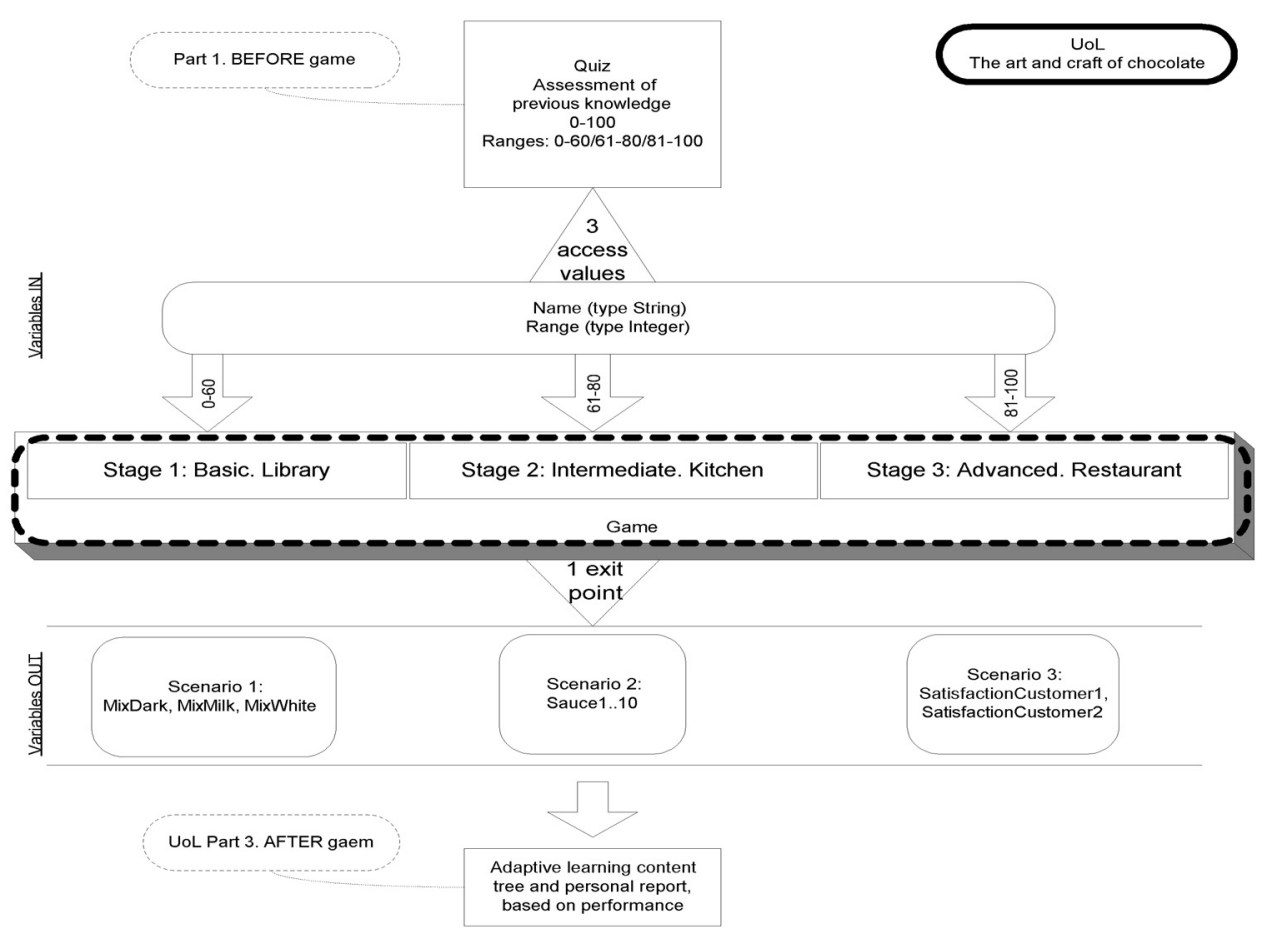


The eGame pursues several didactic objectives, focused on learning:

- how to make the right combination of the basic elements of chocolate to produce the base mix

- how to elaborate different chocolate-based sauces

- how to marry a few chocolate sauces with a selection of dishes.

The third part is a practical exercise with customers, where the learner should get the perfect marriage between the dishes selected by these customers and the available sauces. The student's final grade depends on the satisfaction of each customer who attended.

Depending on the score in the quiz, the student will directly enter into one of the three stages in the eGame, where there are control questions. When the answer to one of these questions is not right he/she receives the right answer and he/she is sent back to the previous stage. When the control question for direct access to Stage 2 is correct, the student automatically receives two mixes (dark and milk). The student is allowed to return to Stage 1 to make more mixes at any time. When the control question for direct access to Stage 3 is correct, the student will be automatically provided with three sauces to be used in the game. The student is allowed to come back to Stage 2 to make more sauces at any time.

Once the game is over, several variables are sent back, stating each customer's satisfaction level and which of the possible sauces were actually prepared. The UoL takes these results on the learner's performance and provides one adaptive learning path out of three possible alternatives.

\subsection{Authoring process}

The UoL focuses on adaptive learning and personalised feedback. It is based on the UoLs Geo-Quiz 1 and Geo-Quiz 3 (LN4LD, 2005) and deals with Level B elements like Properties, Conditions and Calculations to define the questions and get the appropriate results out of the user's answers (Figure 5). It also shows and hides different areas depending on the actual moment of the run, and provides adaptive feedback based on the user's performance. It was authored with XML Spy (Altova, 2006).

Figure 5 Fragment of the UoL The Art and Craft of Chocolate. It shows the use of the property Answerl in a condition to assign a score to the property Value 1

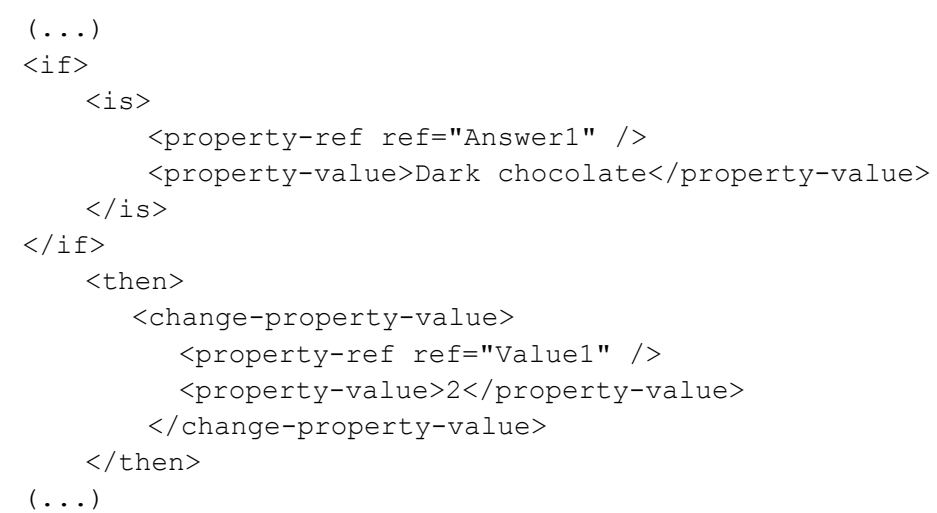


The game itself has been defined in parallel, because the adapter can handle the necessary transformations to align (i.e., to translate) the values and variable names used in the UoL and in the <e-Adventure > game. The process of writing the adventure starts with the elaboration of the storyboard following a number of guidelines that will facilitate the mark-up process according to the principles of descriptive mark-up (Goldfarb, 1981). The development of the game itself is a well-studied development process and it is described in greater detail in Moreno-Ger et al. (2006). In Figure 6 we show a fragment of the <e-Adventure $>$ storyboard produced. This storyboard can be readily edited with a standard XML-editing tool.

Figure 6 Fragment of the <e-Adventure> storyboard for The Art and Craft of Chocolate game. It corresponds to the description of an object (a cookbook). Notice the use of conditions and effects, which are formulated in terms of flags, in the 'examine' action

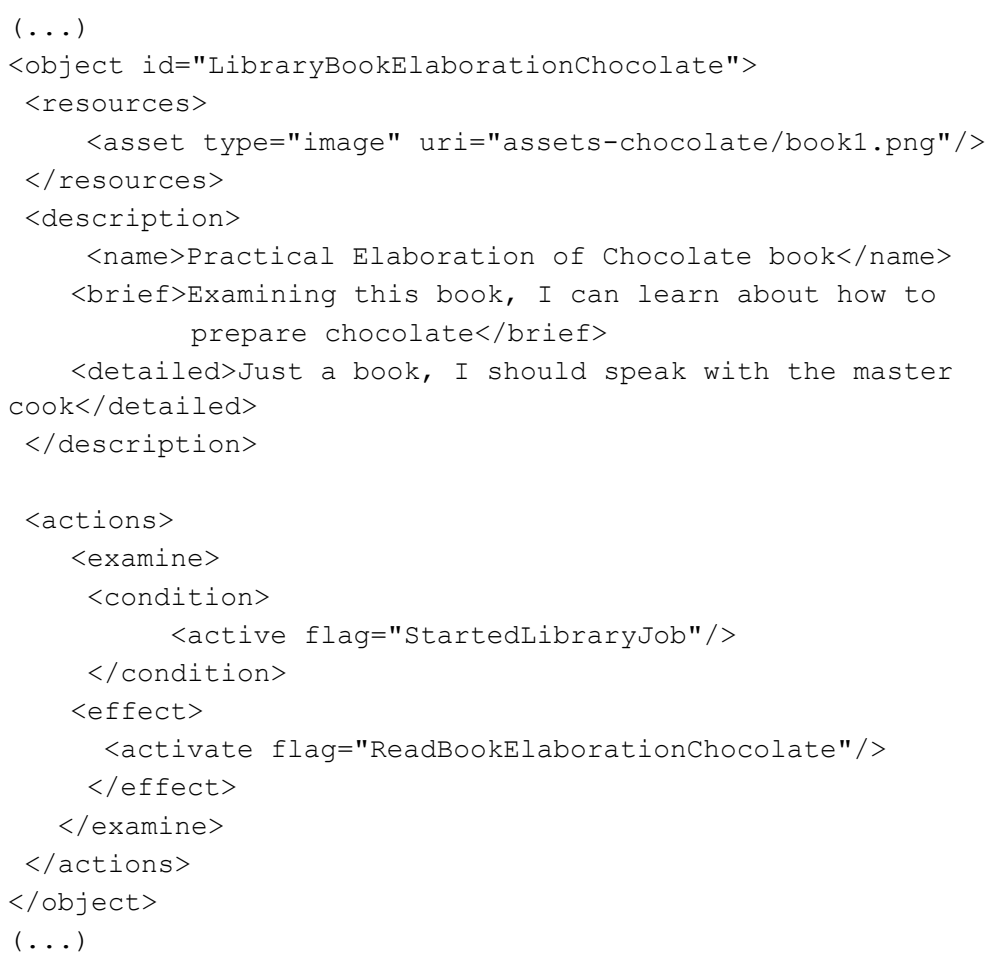

However, it has already been mentioned that the communication with the IMS LD raises additional authoring issues: It is necessary to adapt the values used inside the UoL and the $<\mathrm{e}$-Adventure $>$ documents for both directions of the communication.

On the one hand, for the communication from the UoL towards <e-Adventure $>$ with adaptation purposes, a document like the one described in Section 4.1 was created. In particular, the first part of the UoL sets two very specific properties indicating the level of the student according to his or her responses to the quiz questions. The input configuration file for the adapter indicates which internal flags in the eGame should be activated to alter the behaviour of the game so that the simpler parts can be skipped. In Figure 7 we outline a fragment of this document, which can also be edited using an 
XML-based editing tool. Nevertheless, given the data-centric nature of the underlying mark-up language, we are also developing a specific form-based tool for facilitating this edition task to authors.

Figure 7 Example of adaptation rules for the game in the case study. The pedagogical variables in the UoL that refer to the results in the previous quiz are used to set the flag in the eGame that disabled the first game's level

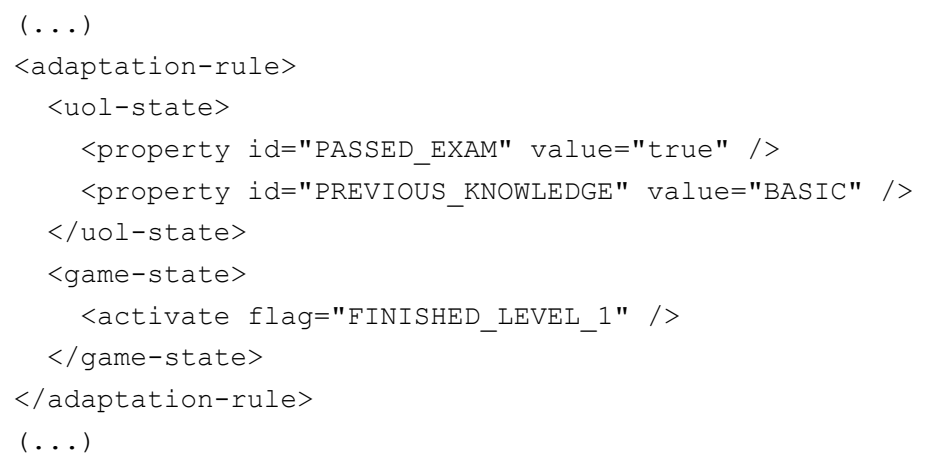

On the other hand, for communication from the <e-Adventure> engine to the UoL with assessment purposes, a different document was created, using the syntax proposed in Section 4.2. Again an XML editing tool was used, although we are working on a form-based specific editor. The eGame keeps Boolean flags indicating which dishes with which sauces were served to each customer. The output configuration contains rules that associate dishes delivered with scores that will be reported to the IMS LD environment, thus affecting the path followed in the third part of the UoL. In Figure 8 we show a fragment of the resulting document.

Figure 8 Example of assessment rules for the game in the case study. Significant flags in the eGame are used to set a pedagogical variable in the UoL related to a mark

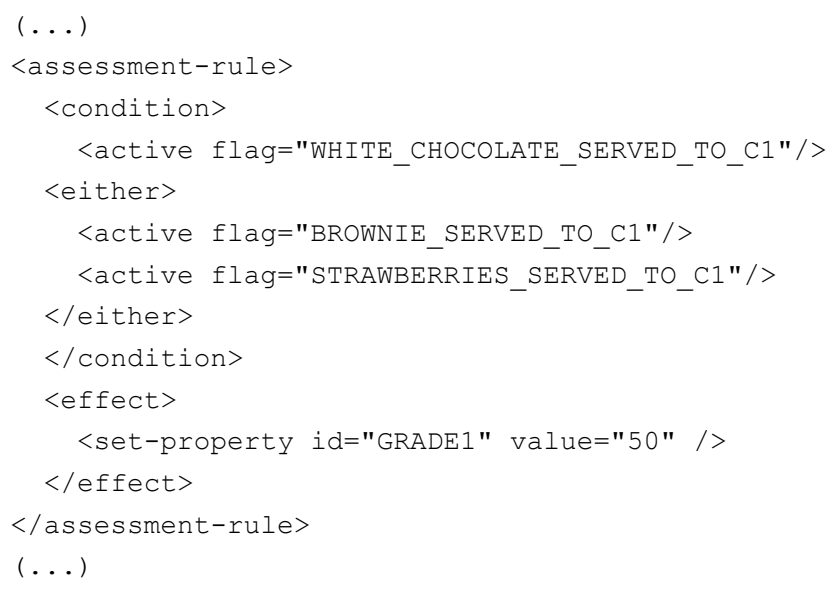




\subsection{Some technical remarks}

Technically, this UoL, which is fully functional, can be authored using any standard IMS LD authoring tools (Bolton, 2004; Miao, 2005) or even any XML editing tool (Altova, 2006). Moreover, the game was authored using the <e-Adventure $>$ language and was integrated in the UoL using the adaptation and the assessment/reporting languages that we have presented in this paper. Following this relation, the UoL can be deployed in a CopperCore + SLeD based environment, which has been extended by the authors with plug-ins supporting the communicator dispatcher described in this paper. The eGame is delivered using the <e-Adventure $>$ engine. This entire supporting environment is also fully functional. It is able to support the authoring and deployment not only of this UoL, but also of any similar UoL that integrates an <e-Adventure $>$ game.

The authors' research teams have participated in the development of all the technologies used in this paper: OUNL leading the IMS LD specification, CopperCore, and SLeD (this one along with Open University UK); and UCM leading the $<$ e-Adventure > Project. The communication dispatcher described in this paper has been jointly implemented by both teams using the integration capabilities of CooperCore + SLeD (see OUNL, 2002). This is based on previous work on the integration of external systems with IMS LD-compliant environments, e.g., the one focused on combining IMS LD and IMS QTI by using the CopperCore Service Integration layer described in Vogten et al. (2006). Finally, the implementation of the UoL itself has also been developed by both teams.

\section{Conclusions and future work}

In this paper we have proposed an authoring approach for adaptive UoL with embedded adaptive eGames. The introduction of the communication mechanism between UoL and eGames raises new and important issues when it comes to authoring the adaptive courses and/or UoLs. With the objective of allowing teachers and learning designers to model rich lectures, full of interactive learning objects, educational objectives and tasks, it is necessary to provide the proper authoring tools.

As has been described, there are several tools and approaches to IMS LD authoring that cover the authoring needs as far as the description of the general learning model is concerned, but none of these tools supports the introduction of eGames that integrate the learning flow as described in this work. Moreover, the development of the games is by itself an additional issue.

There are several projects and initiatives that facilitate the development of eGames for authors without a programming background, the GameMaker (Overmars, 2004) being one of the most relevant works in the academic field. However, it does not support the kind of communication with the learning flow that we are describing here. On the other hand, our <e-Adventure> engine supports this kind of communication and, being based on XML technologies, it also facilitates the declarative definition of the translation rules described in Section 4. Thus, the three authoring processes (UoL, eGame and the translations that allow both elements to communicate) are related and their joint use is relatively straightforward. However, even if this approach represents an improvement 
over programming-based approaches, it is still a complex and error-prone task for regular users with little technical background when compared to approaches based on Graphical User Interfaces.

Given this situation, two main lines of work are foreseen. The first one points to the real use of this authoring setting for adaptive educational games with actual teachers and students. This goal is double-sided: teachers should practise the process and the making of IMS LD UoLs with embedded eGames made with <e-Adventure>, and students should follow the course created. Both user groups would provide extremely valuable feedback based on practice.

Second, the development of graphical tools can make the creative process easier and suitable for every creator-teacher-learning designer, resulting in a lower technological threshold. This is still an open research question (Burgos et al., 2005) for the IMS LD specification and the inclusion of the additional complexities described in this work adds relevance to the problem.

Finally, we also expect to apply this approach to other genres of video games. As indicated in Moreno-Ger et al. (2006), it could suppose the development of new domain-specific languages to facilitate authoring, as well as to support those languages with suitable game engines. Besides, a more systematic approach to the alignment (i.e., translation) of the game's states with the UoL properties is another open research question.

\section{Acknowledgements}

This paper is partially supported by the European projects TENCompetence (IST-TEL/2004-2.4.10, www.tencompetence.org) and ProLearn (IST 507310, www.prolearn-project.org), and the research group <e-Ucm $>$ (www.e-ucm.es). The Education and Science Spanish Committee (projects MetaLearn - TIN2004-08367-C02 -02 - and OdA Virtual - TIN2005-08788-C04-01) and the Regional Government/ Complutense University of Madrid (grant 4155/2005 and research group 910494) have also partially supported this work. Special thanks to Bruno Torijano Bueno for his participation in the creation and preliminary tests of the sample game.

\section{References}

Altova (2006) 'XML Spy Editor', http://www.altova.com (retrieved 18 December 2006).

Bolton (2004) 'Reload project', www.reload.ac.uk (retrieved 16 April 2006).

Burgos, D., Arnaud, M., et al. (2005) IMS Learning Design: la flexibilité pédagogique au service des besoins de la e-formation, La Revue de l'EPI.

Burgos, D., Tattersall, C., et al. (2006a) 'Can IMS Learning Design be used to model computer-based educational games?', Binaria, p.5, www.uem.es/binaria.

Burgos, D., Tattersall, C., et al. (2006b) 'Representing adaptive and adaptable units of learning. How to model personalized eLearning in IMS Learning Design', in B. Fernández Manjon, J.M. Sanchez Perez, J.A. Gómez Pulido, M.A. Vega Rodriguez and J. Bravo (Eds.) Computers and Education: E-learning - From Theory to Practice, Germany: Kluwer.

Burgos, D., Tattersall, C., et al. (2006c) 'Re-purposing existing generic games and simulations for e-learning', Computers in Human Behavior. 
Coombs, J.H., Renear, A.H., et al. (1987) 'Markup systems and the future of scholarly text processing', Communications of the ACM, Vol. 30, No. 11, pp.933-947.

Cordova, D.I. and Lepper, M.R. (1996) 'Intrinsic motivation and the process of learning: beneficial effects of contextualization, personalization, and choice', Journal of Educational Psychology, Vol. 88, No. 4, pp.715-730.

Eskelinen, M. (2001) 'The gaming situation', Game Studies, Vol. 1, No. 1.

Garris, R., Ahlers, R., et al. (2002) 'Games, motivation, and learning: a research and practice model', Simulation \& Gaming, Vol. 33, No. 4, pp.441-467.

Gee, J.P. (2003) What Video Games Have to Teach Us About Learning and Literacy, New York: Palgrave Macmillian.

Gee, J.P. (2005) 'How would a state of the art instructional video game look like?', Innovate Journal of Online Education, Vol. 1, No. 6.

Goldfarb, C.F. (1981) 'A generalized approach to document markup', ACM SIGPLAN Notices, Vol. 16, No. 6, pp.68-73.

IMSCP (2001) 'IMS content packaging', www.imsglobal.org (retrieved 10 May 2006).

IMS LD (2003) 'IMS Learning Design', http://www.imsglobal.org/learningdesign/index.cfm (retrieved 3 November 2006).

Jenkins, H. and Squire, K. (2003) 'Understanding civilization (III)', Games Magazine, September.

Koper, R. and Burgos, D. (2005) 'Developing advanced units of learning using IMS Learning Design level B', International Journal on Advanced Technology for Learning, Vol. 2, No. 3.

Koper, R. and Tattersall, C. (Eds.) (2005) Learning Design - A Handbook on Modelling and Delivering Networked Education and Training, Heidelberg: Springer Verlag.

Laurillard, D. (1998) 'Multimedia and the learner's experience of narrative', Computers in Education, Vol. 31, pp.229-243.

LN4LD (2005) 'Units of learning developed by several authors at Learning Network for Learning Design of the Open University of the Netherlands', http://imsld.learningnetworks.org/course/ view.php?id=20 and http://dspace.ou.nl (retrieved 6 March 2006).

Malone, T.W. and Lepper, M.R. (1987) 'Making learning fun: a taxonomy of intrinsic motivations for learning', in R.E. Snow and M.J. Farr (Eds.) Aptitude, Learning and Instruction III: Cognitive and Affective Process Analysis, Hillsdale, NJ: Lawrence Erlbaum, pp.223-253.

Martinez-Ortiz, I., Moreno-Ger, P., et al. (2006) 'Production and deployment of educational videogames as assessable learning objects', First European Conference on Technology Enhanced Learning (ECTEL 2006), Lecture Notes in Computer Science, Crete, Greece: Springer.

Mernik, M., Heering, J., et al. (2005) 'When and how to develop domain-specific languages', ACM Computing Surveys, Vol. 37, No. 4, pp.316-344.

Miao, Y. (2005) Cosmos LD Editor.

Moreno-Ger, P., Martínez-Ortiz, I., et al. (2006) 'Language-driven development of videogames: the <eGame> experience', 5th International Conference in Entertainment Computing (ICEC 2006), Lecture Notes in Computer Science, Cambridge, UK: Springer.

Moreno-Ger, P., Sierra, J.L., et al. (2007) 'A documental approach to adventure game development', Science of Computer Programming, Vol. 67, No. 1, pp.3-31.

OUNL (2002) 'Dspace', http://dspace.learningnetworks.org (retrieved 16 December 2006).

OUUK (2005) ‘Sled player', http://sled.open.ac.uk (retrieved 13 April 2006).

Overmars, M. (2004) 'Teaching computer science through game design', IEEE Computer, Vol. 37 , No. 4, pp.81-83.

Prensky, M. (2001) Digital Game-based Learning, New York: McGraw-Hill.

Provenzo, E.F. (1991) Video Kids: Making Sense of Nintendo, Cambridge, MA: Harvard University Press. 
Richards, G. (2005) 'Designing educational games', in R. Koper and C. Tattersall (Eds.) Learning Design: A Handbook on Modelling and Delivering Networked Education and Training, Germany: Springer Verlag, Chap. 13.

Rieber, L.P. (1996) 'Seriously considering play: designing interactive learning environments based on the blending of microworlds, simulations and games', Educational Technology Research and Development, Vol. 44, No. 2, pp.43-58.

Sierra, J.L., Fernández-Manjón, B., et al. (2005a) 'Document oriented development of content-intensive applications', International Journal of Software Engineering and Knowledge Engineering, Vol. 15, No. 6, pp.975-993.

Sierra, J.L., Fernández-Valmayor, A., et al. (2004) 'ADDS: a document-oriented approach for application development', Journal of Universal Computer Science, Vol. 10, No. 9, pp.1302-1324.

Sierra, J.L., Navarro, A., et al. (2005b) 'Incremental definition and operationalization of domain-specific markup languages in ADDS', ACM SIGPLAN Notices, Vol. 40, No. 12, pp.28-37.

Specht, M. and Burgos, D. (2006) 'Implementing adaptive educational methods with IMS learning design', Adaptive Hypermedia 2006, Dublin, Ireland.

Squire, K. (2002) 'Video games in education', International Journal of Intelligent Simulations and Gaming, Vol. 2, No. 1.

Tattersall, C., Manderveld, J., et al. (2003) 'IMS Learning Design frequently asked questions', http://dspace.learningnetworks.org/handle/1820/116.

TENCompetence (2005) 'TENCompetence project', www.tencompetence.org (retrieved 31 July 2006).

UCM (2006) 'Complutense University. <e-Ucm> research group', www.e-ucm.es (retrieved 18 December 2006).

Van der Vegt, W. (2005) 'CopperAuthor', www.copperauthor.org (retrieved 13 April 2006).

Vogten, H. and Martens, H. (2005) 'CopperCore 3.0', www.coppercore.org (retrieved 13 April 2006).

Vogten, H.M.H., et al. (2006) 'CopperCore service integration, integrating IMS Learning Design and IMS question and test interoperability', 6th IEEE International Conference on Advanced Learning Technologies, Kerkrade, the Netherlands: IEEE Computer Society Press.

W3C (2003) 'Extensible Markup Language (XML)', http://www.w3.org/XML/ (retrieved 18 December 2006). 